\title{
Qualitative Phytochemical Analysis and Antibacterial Potential of Chromolena Odorata Leaves as affected by Soxhlet and Maceration Extraction
}

\author{
Nur Farahida Mohd Shamsuddin Tan ${ }^{1}$, Noor Akhmazillah Mohd Fauzi ${ }^{1 *}$, Aliff \\ Hisyam A. Razak ${ }^{1}$, Sity Aisyah Mansur ${ }^{1}$
}

${ }^{1}$ Department of Chemical Engineering Technology, Faculty of Engineering Technology, Universiti Tun Hussein Onn Malaysia (UTHM), Pagoh Education Hub, KM1, Jalan Panchor, 86400 Panchor, Muar Johor, MALAYSIA

*Corresponding Author

DOI: https://doi.org/10.30880/jaita.2020.01.02.006

Received 07 July 2020; Accepted 18 November 2020; Available online 15 December 2020

\begin{abstract}
Chromolaena odorata is locally known as "Pokok Kapal Terbang”. This species is a perennial weed of plantation crops and cleared lands and it comes from the family of Asteraceae (Compositae) and can be found abundantly in Malaysia. The fresh leaves and extract of this plant commonly related to herbal treatment in some developing countries for burns, soft tissue wounds, and skin infections. However, it has not been thoroughly investigated and their phytochemical and cytotoxicity potential virtually unknown. The objective of this study is to investigate the antibacterial potential of $C$. odorata leaves extract and its phytochemicals content. The Soxhlet and maceration methods of extraction were carried out and then were tested for its phytochemicals content namely saponins, terpenoids, tannin and flavonoids. The antibacterial activity of extracted samples was tested against gram-positive Staphylococcus epidermidis and gram-negative Escherichia coli by using the disc diffusion method. The results showed that the percentage yield of leaves extract using the Soxhlet method for 12 hours was $21.60 \%$, which is higher than the maceration method (with $18.10 \%$ of yield for 120 hours extraction). Qualitative phytochemicals analyses revealed that both Soxhlet and macerationextracted of $C$. odorata leaves contain tannins, flavonoids, saponins and terpenoids. All the extract showed a good antibacterial properties against both $S$. epidermidis and E.coli strain with inhibition zone ranging from $8.33 \mathrm{~mm}$ to $11.00 \mathrm{~mm}$ and $6.00 \mathrm{~mm}-10.50 \mathrm{~mm}$, respectively. The extract was then further applied onto cream and the anti-bacterial activity against S.epidermidis was recorded in which the largest inhibition zone of 9.50 $\mathrm{mm}$ was obtained. Whereas anti-bacterial activity against $E$. coli was found only in Soxhlet extracted sample (12 hours treatment time) with $12.00 \mathrm{~mm}$ diameter of inhibition zone. This study showed that $C$. odorata leaves extract has a great potential to be developed as an antibacterial agent which can be incorporated with cream for medical and pharmaceutical use.
\end{abstract}

Keywords: Chromolaena odorata, Soxhlet extraction, Maceration extraction, Antibacterial, Phytochemicals

\section{Introduction}

Medicinal plants are good sources of secondary metabolites, which exhibit therapeutic effects. These are called phytochemicals include alkaloids, glycosides, terpenoids, flavonoids, and phenols [1]. Phytochemicals in medicinal plants can be used directly for therapeutic purposes or as a precursor for the synthesis of pharmaceuticals [2]. Some of these medicinal plants are variously used as food and mostly cultivated, while a number of plants growing in the wild are strictly used for therapeutic applications $[1,2]$. Such wild plants are sometimes added to foods for medicinal purpose [3]. 
Tannins are antiseptic in nature and hasten the healing of wounds [4]. Flavonoids have been shown to exhibit pharmacological effects as, anti-inflammatory, antioxidant, anti-antibacterial agents [5, 6]. Saponins defend plants against microbial attack, hence serve as antimicrobial and antifungal agents to humans and are applied as a cough remedy [7]. Although modern medicinal science has been developed to a great extent, many rural people still depend on plant products and herbal remedies for treating their ailments. About 17,631 species of flora grow in its forests, jungles, wastelands, and roadside as indigenous, naturalized and cultivated plants. Out of them, more than a thousand have their medicinal and therapeutic use $[8,9]$.

Chromolaena odorata (L.) is a member of the family Compositae (Asteraceae), which is a very large cosmopolitan family [10] and consists of 13 tribes, 84 genera and over 240 species [1]. The ornamental plant usually considered to be one of the top 100 most invasive environmental weeds of wastelands, roadsides and other exposed areas in the world [11]. It is known that the C. odorata plants usually get thrown away due to it fast growth and potentially can damage cultivation plants and consequently bring a cost to the farmers. However, not many people know that C. odorata can contribute to some benefits to farming [9]. The nutrition content in C. odorata leaves such as phenol, alkaloids, tannin, and flavonoid can give benefits to not only farming but also the body's health [12]. Usually, C. odorata is also used a lot as traditional herb medicines. The decoction of the leaves and stems are reported to be effective against the treatment of skin disease like Propionibacterium acnes [12]. It is also used for healing wounds, effective against KI strain of Plasmodium which causes malaria, possesses anti-inflammatory, analgesic, antioxidant and antifungal activities [11].

Nowadays, the herb is highly used in cosmetics which are used to incorporate medicine elements in the cosmetic product. Cosmeceutical is the combination of medicine elements (extracted from the herb/medicinal plant) with a cosmetic product. Cosmeceutical cream with the incorporation of $\mathrm{C}$. odorata leaves extract is believed to improve the skin biological function by using organic ingredients $[12,13]$. Besides, it is functioning as a wound-healing agent due to its antioxidant, anti-inflammatory, analgesic, anti-microbial, cytoprotective and many other medicinally significant properties. This cosmeceutical cream also has a function of pharmaceutical product where flavonoids, triterpenes, chalcones, and steroids are a bioactive compound which was isolated from C. odorata are responsible for its pharmacological activities.

Maceration and Soxhlet extraction are the traditional methods that are commonly used at the small research level. Maceration is a technique involved soaking the plant in a stoppered container with a solvent and allowed to stand at room temperature for a specific time, with frequent agitation. Meanwhile, for the Soxhlet extraction process, the sample is placed in the thimble, and this thimble put in down into the thimble chamber of the Soxhlet apparatus. The extracting solvent is heated, and its vapors condense in condenser and drip back. Liquid content were then reaches the siphon arm and emptied into the bottom flask again and the process is continued.

Although Malaysia is listed as one of the mega-biodiversity countries with various species of flora, unfortunately, many plants in Malaysia have not been thoroughly investigated and their phytochemical and cytotoxicity potential virtually unknown. Hence, the current study is undertaken to inch through and narrow the huge gap of basic studies on native plants in Malaysia. For the reason, this study was focused on the potential of C. odorata leaves extract as herbal medicine by extracting their bioactive compounds such as tannins, terpenoid, flavonoids and saponins that may possess with antibacterial properties in nature for the healing of a wound [13]. In addition, this study is conducted to evaluate the antibacterial potential of the ethanolic extract of $\mathrm{C}$. odorata leaves against human pathogens namely Escherichia Coli and Staphylococcus epidermidis. The use of C. odorata as an antibacterial agent can be utilized as a sustainable cosmeceutical and pharmaceutical product for the near future due to its characteristics which is abundantly grown and easily discovered in Malaysia.

\section{Methods}

\subsection{Material and Sample Preparation}

In this research, fresh leaves parts of C. odorata (Fig. 1) were collected from the Nasuha Herb \& Spice Farm located in Muar, Johor. C. odorata leaves were washed under running tap water to remove extraneous materials. The leaves were drying in the oven at a temperature of $30{ }^{\circ} \mathrm{C}$ for 7 days and pulverized using a grinder. The respective powders were stored as stock in air-tight containers until used.

\subsection{Extraction (Soxhlet and Maceration method)}

\subsubsection{Soxhlet Extraction}

Ten (10) grams of powdered sample was extracted with $150 \mathrm{~mL}$ of $90 \%$ ethanol (as a solvent) by using assembled Soxhlet apparatus. The temperature level of the heating mantle was adjusted to the heating stage of 3 for 4 hrs and 24 hrs. The resulted dark-green extract was then concentrated up to $10 \mathrm{~mL}$ using a rotary vacuum evaporator under reduced pressure $(58 \mathrm{mbar})$ at $34^{\circ} \mathrm{C}$. Crude extracts were collected until a thick and viscous paste of extract was visible The extract was then stored in a refrigerator at $4^{\circ} \mathrm{C}$ until used $[14,15]$. 


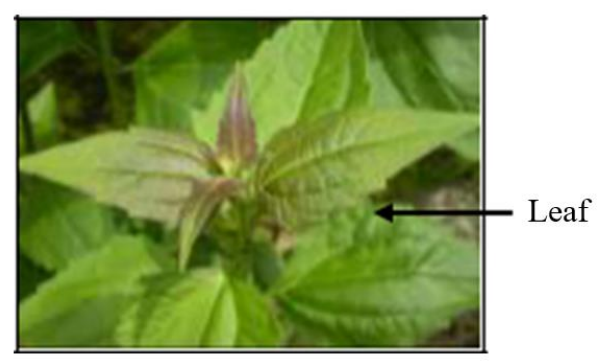

Fig. 1 - Chromolaena odorata plant obtained from Nasuha Herb \& Spice Farm

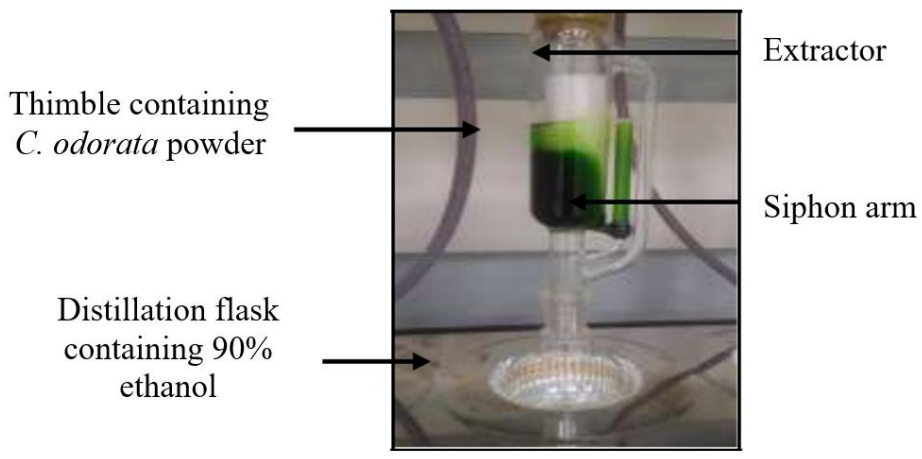

Fig. 2 - A diagram for Soxhlet extraction technique carried out in this study

\subsubsection{Maceration Extraction}

Ten (10) $\mathrm{g}$ of powdered C. odorata were soaked with $150 \mathrm{~mL}$ of ethanol solvent in a $100 \mathrm{~mL}$ glass conical flask. The conical flask is sealed with parafilm and wrapped with aluminium foil to prevent solvent loss and exposure of light (Figure 3) The mixture was then shake using a mechanical shaker for 48 and 120 hours at room temperature. The extracts were then filtered using a vacuum pump. Then, the collective extracts were concentrated using a rotary evaporator at $34{ }^{\circ} \mathrm{C}$ before weighted and stored in refrigerators at a temperature of $4{ }^{\circ} \mathrm{C}[16,17]$.

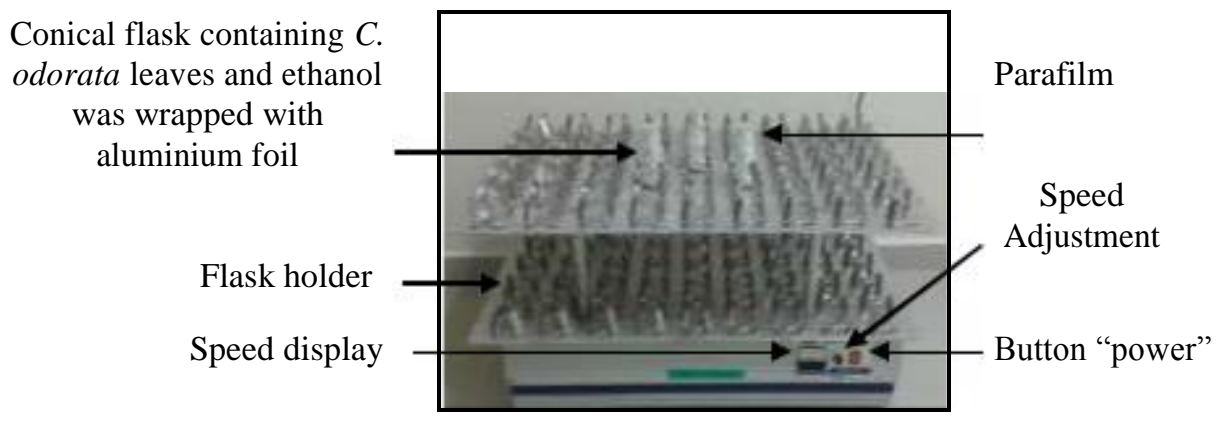

Fig. 3 - A maceration extraction technique carried out in this study

\subsection{Preliminary Phytochemical Screening}

The following tests are carried out to determine the presence or absence of phytochemicals:

\subsubsection{Test for tannins}

The presence of tannins in the test samples was carried out using the ferric chloride test described by Harborne [18]. $2 \mathrm{~mL}$ of the aqueous extract was added into a test tube, 10 drops of $1 \%$ ferric chloride $(\mathrm{FeCl})$ was added to the mixture. The formation of a dark green indicated the presence of tannins. 


\subsubsection{Test for flavonoids}

$4 \mathrm{~mL}$ aqueous $\mathrm{NaOH}$ was added to $2 \mathrm{~mL}$ of each ethanol extract. Observation on yellow precipitate indicated the presence of flavonoids in the extract. The confirmatory test was carried out by adding a few drops of concentrated hydrochloric $(\mathrm{HCl})$ into the yellow solution which turned colorless [19].

\subsubsection{Test for saponins}

The presence of saponins in the test samples was investigated as described by Harborne [18]. $2 \mathrm{~mL}$ of the extract was mixed with $6 \mathrm{~mL}$ of distilled water in a test tube. The mixture was shaken well and the formation of froth indicated the presence of saponins.

\subsubsection{Test for terpenoids}

The presence of terpenoids is carried out using the Salkowski test [18]. About $2 \mathrm{~mL}$ of the extract is mixed in $2 \mathrm{~mL}$ of chloroform in a test tube and $3 \mathrm{~mL}$ of concentrated sulphuric acid (H2SO4) is carefully added to form a lower layer. A reddish-brown color interface is indicative of the presence of terpenoids.

\subsection{Antibacterial activity testing}

The extracted samples were tested for their antibacterial activity by using the agar-disc diffusion method. The general procedure for the agar-disc diffusion method is depicted in Figure 4.

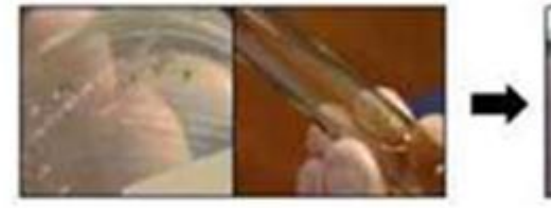

Preparation of inoculum

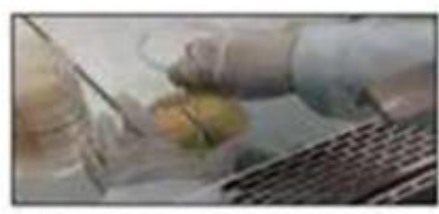

Place $0.3 \mathrm{~mL}$ of broth culture on the agar and spread using glass spreader

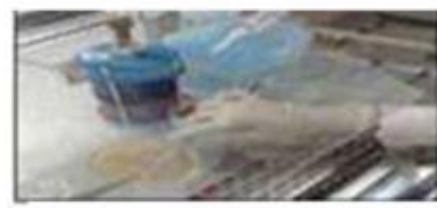

Dried ethanol disc were transferred using forceps onto the surface of agar plates

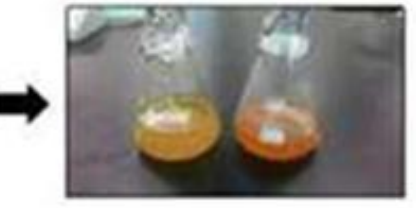

Preparation of nutrient agar

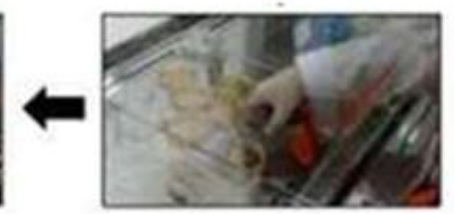

Pour the nutrient agar \& MBS into the petri dish

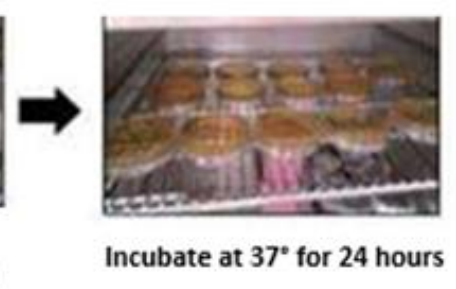

Fig. 4- General procedure for Agar-disc diffusion method

\subsubsection{Innoculum Preparation}

The bacterial organisms of E. coli (ATCC 25922) and S. epidermidis (ATCC 25923) were tested. Before use, the microbes were subcultured on a sterile nutrient agar plate, incubated aerobically at $37^{\circ} \mathrm{C}$ for 24 hours.

\subsubsection{Media preparation}

The media used for culturing the organism were nutrient agar for Escherichia coli and Mueller Hinton Agar (MHA) for Staphylococcus epidermidis. Nutrient agar was prepared by dissolving $10 \mathrm{~g}$ of agar powder in $500 \mathrm{~mL}$ of distilled water and autoclaved (Hirayama HVE-50, Japan) at $121^{\circ} \mathrm{C}$ for 15 minutes and allowed to cool to body temperature. The media was dispensed into petri dishes. Mueller Hinton Agar media was prepared by dissolving $9 \mathrm{~g}$ of 
agar powder in $237 \mathrm{~mL}$ of distilled water. It was autoclaved for 15 minutes at $121^{\circ} \mathrm{C}$ and allowed to cool to room temperature before dispensing into petri dishes [8].

\subsubsection{Preparation of Disc}

Disc of diameter $5 \mathrm{~mm}$ was perforated from Whatman filter paper (1) using a perforator. The discs were sterilized using a bijou bottle at $160^{\circ} \mathrm{C}$ for 2 hours in a hot air oven (Memmert, German). It was brought out and allowed to cool before further use [20].

\subsubsection{Disc Preparation for Ethanolic Extract}

$0.5 \mathrm{~g}$ of ethanol extract of leaves were mixed with $2 \mathrm{~mL}$ of water. The mixture was properly done in a test tube and $1 \mathrm{~mL}$ of the mixture was poured into a glass petri dish containing 5 paper discs. The disc was put in the oven for $3 \mathrm{hrs}$ at $40{ }^{\circ} \mathrm{C}$ so that the extract would stick to the discs [20].

\subsubsection{Susceptibility Test Using Plant Extract}

Mueller Hinton Agar and nutrient agar plated were inoculated with respective test organisms using pipette followed by spreading using glass spreader for each test organism. The plates were allowed to dry for 15 mins in an incubator (MMM Incucell 222, German). The dried ethanol discs as mentioned above were transferred using flamed but cooled forceps into the surface of the inoculated agar plates. They were sufficiently spaced to prevent the resulting zone of inhibition from overlapping. The plates were incubated at $37^{\circ} \mathrm{C}$ for $18-24 \mathrm{hrs}$ to observe the zone of growth inhibition produced by the extract [21].

\subsection{Formulation of lotion with optimized extracts}

The optimized extract of C.odorata was applied in a lotion formulation to study its antibacterial activity. The lotion base involves simple mixing of $27 \mathrm{~g}$ of deionized water and $3 \mathrm{~g}$ of virgin coconut oil with a ratio of 90:10 (w/w) in a $100 \mathrm{~mL}$ beaker. $1 \%$ of surfactant $(0.3 \mathrm{~g})$ was then added and mixed using a homogenizer. At last, $1 \%$ of extracts $(0.3 \mathrm{~g})$ was added into the prepared lotion base and mixed thoroughly. The formulated lotion transferred into a clean lotion bottle and kept at room temperature $\left(25^{\circ} \mathrm{C}\right)$.

\section{Results \& Discussions}

\subsection{Extracted Yield of C. odorata leaves}

The yield of ethanolic extract of C. odorata after being vaporized using a rotary evaporator was recorded as $1.15 \mathrm{~g}$ ( $11.50 \%$ yield) and $2.16 \mathrm{~g}$ (21.60\% yield) for 4 hours and 12 hours, respectively. The result shows that by using the Soxhlet method, a longer extraction time of 12 hours gave a higher percentage of the yield as compared to 4 hours. The same result was recorded for the maceration extraction method, which is a longer extraction time of 120 hours resulted in a higher crude extract $(1.81 \mathrm{~g}, 18.10 \%$ yield $)$ as compared to the 48 hours $(0.72 \mathrm{~g}, 7.20 \%$ yield $)$. Comparing the extraction effectiveness of these two methods, Soxhlet extraction at 12 hours was more effective as compared to the maceration method. In general, the results show that extraction yield is increased as the extraction is more longer for both methods.

A higher extraction yield by using the Soxhlet method in this study $(11.50 \%$ and $21.60 \%$ for $48 \mathrm{hrs}$ and $120 \mathrm{hrs}$ respectively) was in accordance with previous research [22]. Theoretically, the yield of extraction was depended on the solvent used and extraction time. In this study, $90 \%$ of ethanol was used as a solvent because these mixture (water and alcohol) are both polar and nonpolar, which at this condition, different compounds can be successfully extracted as compared to pure ethanol (100\%). Besides, using water in combination with alcohol leads to an increase in swelling of plant materials and the contact surface area between the plant matrix and the solvent finally improves the extraction yield [23].

Table 1 - Percentage Yield of $C$. odorata leaves extract by using Soxhlet and Maceration extraction methods

\begin{tabular}{|c|c|c|}
\hline \multirow{3}{*}{$\begin{array}{c}\text { Extraction } \\
\text { time }(\mathbf{h})\end{array}$} & \multicolumn{2}{|c|}{ Yield of C. odorata leaf extraction } \\
\hline & \multicolumn{2}{|c|}{ Soxhlet extraction } \\
\hline & Weight of extract (g) & Percentage $(\%)$ \\
\hline 4 & 1.15 & 11.50 \\
\hline 12 & 2.16 & 21.60 \\
\hline & \multicolumn{2}{|c|}{ Maceration extraction } \\
\hline 48 & 0.72 & 7.20 \\
\hline 120 & 1.81 & 18.10 \\
\hline
\end{tabular}




\subsection{Qualitative phytochemical screening}

The qualitative testing was carried out on the extracted sample to investigate the presence of bioactive compounds (terpenoids, saponins, flavonoid and tannin) obtained from C.odorata leaves extract. Table 2 present the result for qualitative phytochemical screening obtained from this study.

Table 2 - Qualitative phytochemical analysis of ethanolic extracts of Chromolaena odorata leaves

\begin{tabular}{ccccc}
\hline Phytoconstituents & \multicolumn{2}{c}{ Soxhlet method } & \multicolumn{2}{c}{ Maceration method } \\
\cline { 2 - 5 } & 4 hours & 12 hours & 48 hours & 120 hours \\
\cline { 2 - 5 } Terpenoids & + & + & + & + \\
Saponin & + & + & + & + \\
Flavonoids & + & + & + & + \\
Tannins & + & + & + & + \\
\hline
\end{tabular}

+ indicates the presence of the compound in the extracted sample

The result shows that all phytochemicals compound tested; terpenoids, saponins, flavonoids, and tannins were observed in the C.odorata leaves extract. The result obtained was in line with previous findings where the ethanolic extract of C.odorata leaves reveals the presence of medicinally valued bioactive components like saponins, tannins, terpenoid, and flavonoids [28]. Besides, other studies also showed that ethanolic extract was rich in secondary metabolites such as alkaloids, flavonoids, tannins, saponins, terpenoids, glycosides, cardiac glycosides, and phenols $[24,25]$.

Figures 5,6, 7 and 8 show the observation of the qualitative test for targeted phytochemical constituents. As depicted in Fig. 5, the formation of reddish-brown color was observed by adding chloroform and sulphuric acid into the ethanolic extract of $C$. odorata leaves, which indicates the presence of terpenoids.

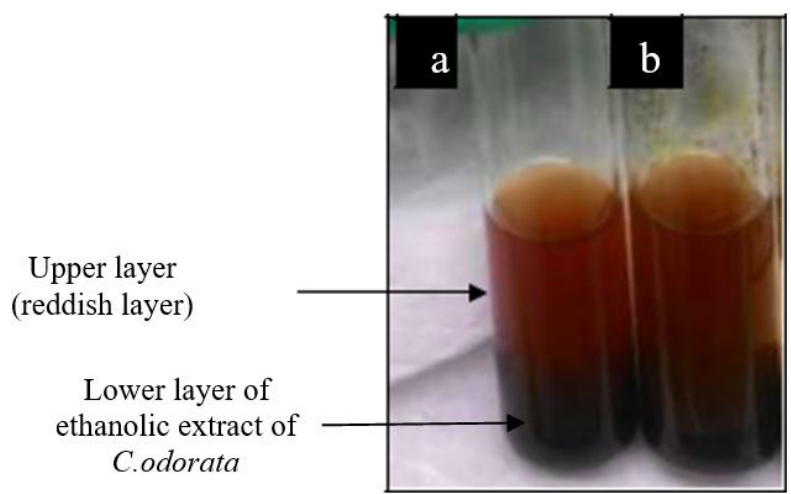

Fig. 5 - Detection of terpenoid in ethanolic extract: (a) 4hrs (soxhlet method) and (b) 48hrs (maceration method)

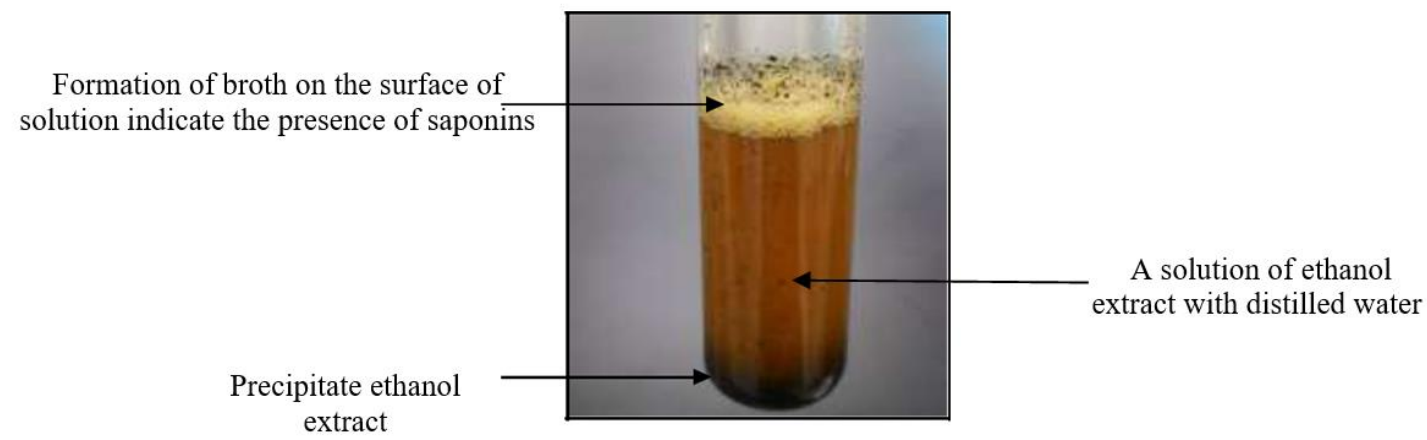

Fig. 6 - Detection of saponins in ethanolic extract for 12 hours (Soxhlet method) 
The presence of saponins in all extracted sample was detected when a mixture of extract and distilled water, formed a broth after shaken for a few minutes (Fig. 6). Figure 7 shows the detection of flavonoids in extracted samples where a colorless solution was formed after being added with $\mathrm{NaOH}$ and concentrated HCL. Whereas for tannin, the dark green color was formed when a fews drop of $1 \%$ of ferric chloride was added into the dilute extracted compounds as shown in Fig. 8.
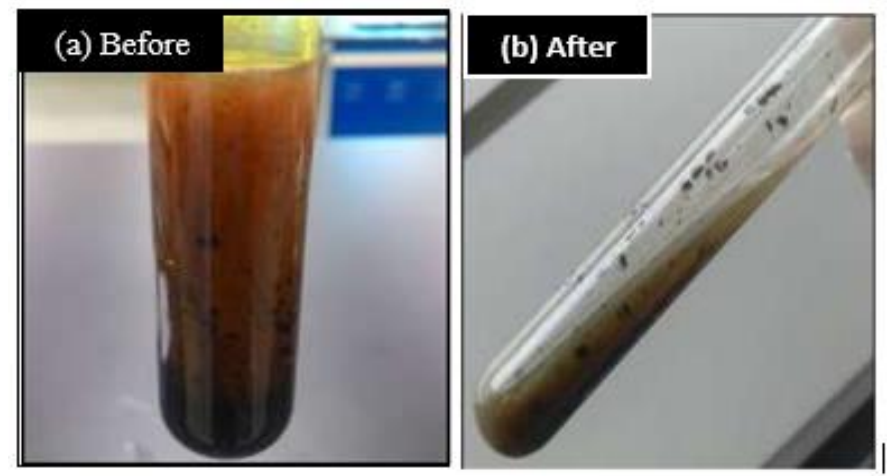

Fig. 7 - Detection of flavonoids for 12 hours extraction: (a) the solution turn into yellowish color after adding $\mathrm{NaOH}$ (b) the yellow solution turned to colorless but chalky after adding a few drop of HCL. This indicateds the presence of flavonoids in the extract

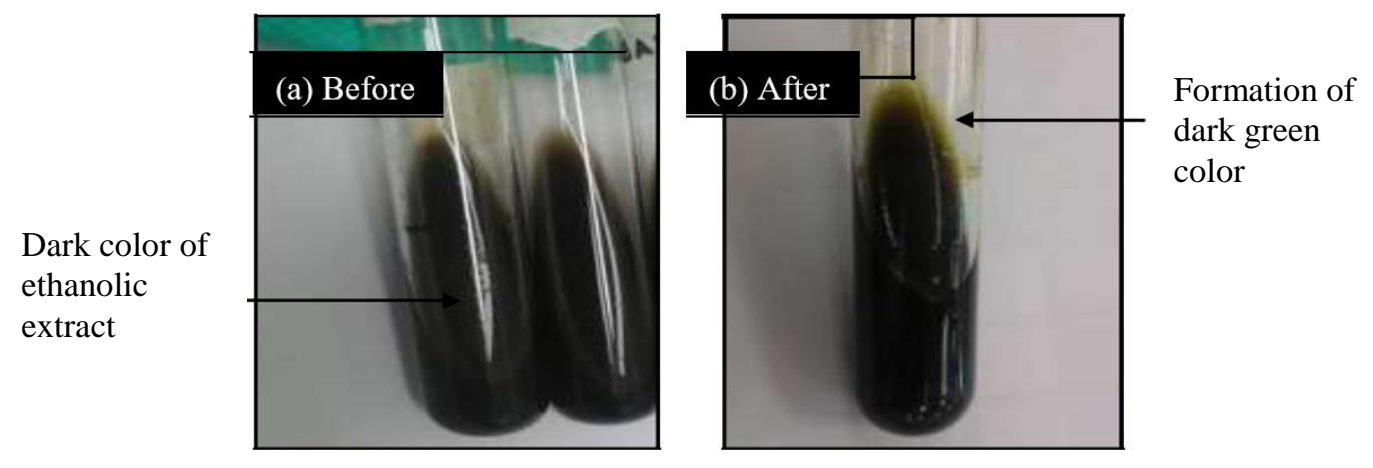

Fig. 8 - Detection of tannins: (a) show the color pure extract before adding ferric chloride for Soxhlet method (4hour) and maceration (48 hours), (b) after a few drop of FeCI was added into the extract dark green color indicates the presence of tannins in the extracted sample

The healing properties of medicinal plants are usually linked with the presence of phytochemicals and these differ compound in one plant has the difference in pharmacological effects. Therefore, the presence of various phytochemicals in $C$. odorata suggests that this plant possesses therapeutic importance [3]. Thus the preliminary screening test was useful in the detection of bioactive principles and subsequently may lead to drug discovery and development. Besides, flavonoids, tannins, saponins, and terpenoids which were extracted from this plant may be responsible for its pharmacological activities as well as a wound-healing agent for pharmaceutical and cosmeceutical use.

\subsection{Antibacterial activity testing}

The antibacterial properties of extracted C.odorata were determined by using the agar-disc diffusion method against different types of pathogens which were E.coli and S.epidermidis. For agar-disc diffusion method, the antibacterial activity of C.odorata extracted was evaluated based on the diameters of clear inhibition zone around the disc located on the agar. No inhibition zone showing that there is no antibacterial activity. Table 3 shows the comparison of inhibition zone diameter for both extracted samples (Soxhlet and maceration) concerning their extraction time against $E$. coli and $S$. epidermidis. The table also shows the inhibition zone of non-extracted samples. 
Table 3 - Inhibition zone of $C$. odorata leaves against $E$. coli and $S$. epidermidis in extracted sample (Soxhlet and maceration) and non-extarcted sample

\begin{tabular}{ccc}
\hline \multicolumn{3}{c}{ Inhibition Zone Diameter $(\mathbf{m m})$} \\
\hline $\begin{array}{c}\text { Without extraction (Powder form, sieved at } 75 \mu \mathrm{m}) \\
\boldsymbol{\mu}\end{array}$ & NA & S. epidermidis \\
\hline Soxhlet extraction & & \\
\hline 4 hours & 9.00 \\
12 hours & 10.50 & 8.33 \\
\hline Maceration extraction & & 11.00 \\
\hline 48 hours & 6.00 & 9.50 \\
120 hours & 8.00 & 9.75 \\
\hline
\end{tabular}

Inhibition strength indicator: (1) Diameter of inhibition zone $\geq 15 \mathrm{~mm}$ : Strong, (2) Diameter of inhibition zone $10 \mathrm{~mm}$ $14.5 \mathrm{~mm}$ : Medium, (3) Diameter of inhibition zone $\leq 9 \mathrm{~mm}$ : Weak, (4) Diameter of inhibition 0 mm: No activity.

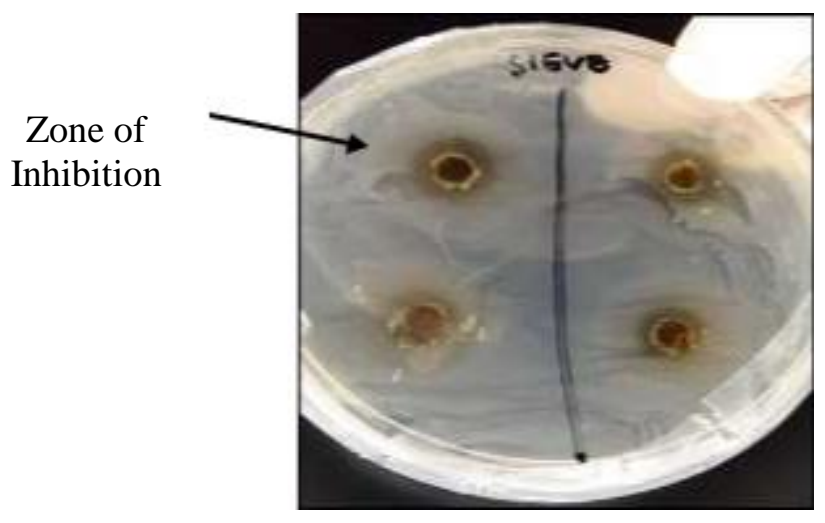

Fig. 9 - Inhibition zone for non-extracted $C$. odorata leaves against S. epidermidis

The result shows that no antibacterial was detected when a non-extracted sample was tested against E.coli. However, $9.00 \mathrm{~mm}$ in diameter of inhibition zone was observed for S. epidermidis (Fig. 9). There is only a slight difference in the inhibition zone of the Soxhlet extracted sample for both E. coli and S. epidermidis. Longer extraction time (12 hours) gave more antibacterial activity for E. coli (with $10.50 \mathrm{~mm}$ in diameter) and S. epidermidis (11.00 mm in diameter) of inhibition zone as compared to 4 hours extraction with $9.25 \mathrm{~mm}$ and $8.33 \mathrm{~mm}$ for $E$. coli and $S$. epidermidis, respectively. Whereas, the maceration extracted sample gave a larger inhibition zone when extraction time was prolonged up to 120 hours with $8 \mathrm{~mm}$ and $9.75 \mathrm{~mm}$ in diameter of inhibition zone for E. coli and S. epidermidis, respectively. Referring to the types of pathogenic bacteria used, S. epidermidis showed more resistance towards maceration extracted samples for both treatment time (48 hours and 120 hours) and Soxhlet extracted sample (12 hours) as compared to E. coli. Figure 10 (a) and (b) show the inhibition zone for ethanolic extract of C. odorata against E. coli for Soxhlet (4 hours and 12 hours) and maceration (48 hours and 120 hours).

Antibiotic cream is used to speed up the healing of a wound and prevent infection. In this study, the antibacterial activity of cream incorporated with $C$. odorata leaves extract is investigated and the result was presented in Table 4. The result shows that no antibacterial was detected when a cream base sample was tested against E.coli and $S$. epidermidis. For Soxhlet extracted of $C$. odorata leaves (4 hours of extraction time) combine with VCO cream base, no antibacterial activities against $E$. coli at was detected, however, $9.00 \mathrm{~mm}$ in diameter of inhibition zone was recorded for $S$. epidermidis. The Soxhlet extracted of $C$. odorata leaves (12 hours of extraction time) combine with VCO cream base gave more antibacterial activity with $12.00 \mathrm{~mm}$ in diameter of inhibition zone against E. coli (Figure 11(a)) as compared to $S$. epidermidis with $8.50 \mathrm{~mm}$ Figure 11(b)). Whereas, the maceration extracted sample gave a larger inhibition zone when extraction time was prolonged up to 120 hours with $7.00 \mathrm{~mm}$ and $9.50 \mathrm{~mm}$ in diameter of inhibition zone for E. coli and S. epidermidis, respectively. For sieve combine VCO cream base against E.coli and S.epidermis, no inhibition on the growth of E.coli and S.epidermidis was observed. 

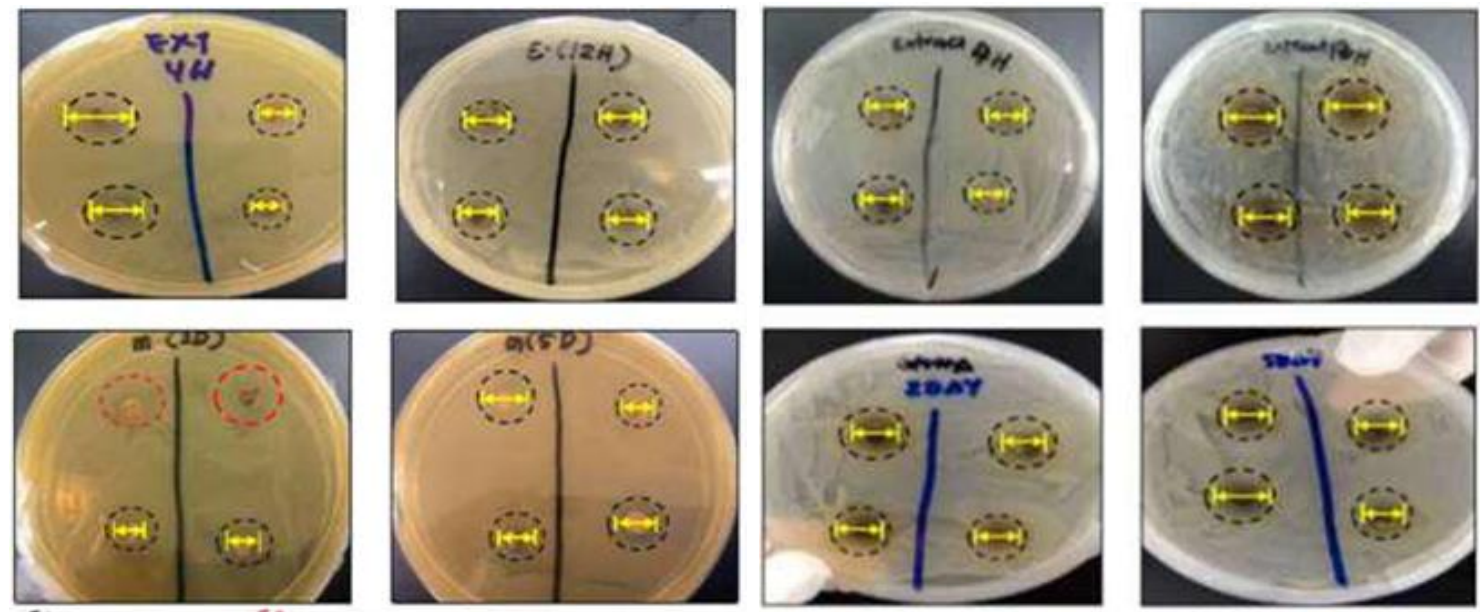

(a)
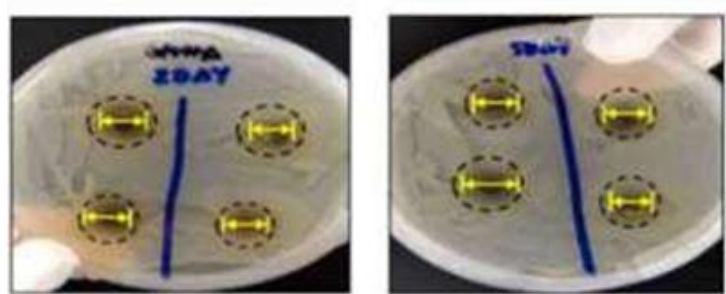

(b)

$\bigcirc$ - Inhibititon zone $\bigcirc$ - No inhibtiton zone $\longleftrightarrow$ - Diameter inhibtition zone

Fig. 10 - Inhibition zone for ethanol extract of Soxhlet and Maceration method against (a) E.coli and (b) S.epidermidis.

Table 4 - Inhibition zone of $C$. odorata leaves against $E$. coli and $S$. epidermidis in extracted sample (Soxhlet and maceration) and non-extarcted sample.

\begin{tabular}{ccc}
\hline & Inhibition Zone Diameter $(\mathbf{m m})$ \\
\hline & E. coli & S. epidermidis \\
\hline VCO cream base & NA & NA \\
\hline Ethanolic extract + VCO cream base (Soxhlet extraction) & 9.00 \\
\hline 4 hours & NA & 8.50 \\
12 hours & 12.00 & \\
\hline Ethanolic extract + VCO cream base (Maceration extraction) & 6.00 \\
\hline 48 hours & NA & 9.50 \\
120 hours & 7.00 & \\
Sieve powder of C.odorata leaves + & NA \\
VCO cream base & NA & \\
\hline
\end{tabular}

In this current study, the gram-positive and gram-negative bacteria (Staphylococcus epidermidis and E.coli) used were both inhibited by the ethanol extracts of C.odorata. S.epidermidis had a higher zone of inhibition as compared to E.coli. On the other hand, the sieved powder of C.odorata leaves incorporated with the VCO cream base did no effect on both S.epidermidis and E.coli. The previous study has revealed that the ethanolic extract of C. odorata was very effective against $S$. epidermidis and E.coli with inhibition diameter zone between $6.00-7.00 \mathrm{~mm}$ [8]. The ability of C.odorata exhibiting antimicrobial activities in this work indicates a potential for alternative use of this plant as raw materials for the production of medicine which can be used in diseases caused by S. epidermidis and E. coli [8].

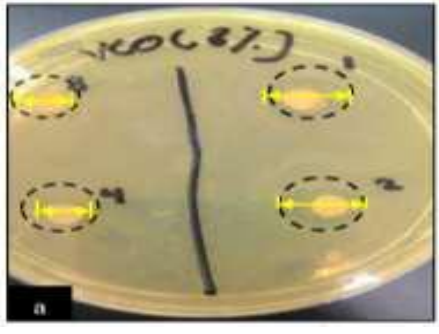

(a)

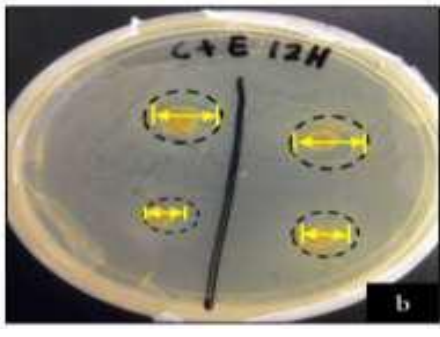

(b)

$\bigcirc$ - Inhibititon zone $\bigcirc$ - No inhibtiton zone $\longleftrightarrow$ - Diameter inhibtition zone

Fig.11 - (a) Inhibition zone for ethanol extract + VCO cream base against E.coli, (b) ethanol extract + VCO cream base against gram positive S.epidermidis for 12 hour (Soxhlet extraction) 


\section{Conclusion}

The present study has successfully shown the C. odorata leaves extract possesses a valuable phytochemicals compound which are tannin, saponins, terpenoids, and flavonoids. The extraction process on C.odorata leaves did not give a significant role in the presence or absence of its phytochemicals. S. epidermidis showed a good response to the antibacterial effect for both non-extracted and extracted samples (Soxhlet and maceration). The study clearly indicated that C. odorata extract contains phytochemical compounds which act as an antibacterial agent for pharmaceutical and cosmeceutical industries.

\section{Acknowledgement}

The first author would like to thank the Innovation and Commercialization Centre, ICC, UTHM for the MTUN Commercialisation Fund (I027) and Research Management Centre for the UTHM Contract Grant (H524). The supply of C. odorata leaves from Nasuha Herb and Spice Farm, Muar, Johor is much appreciated. Special thanks to Mohd Redzuan, Masayu Maslan and Aziah Abu Samah from the Department of Chemical Engineering Technology, Faculty of Engineering Technology for their technical support.

\section{References}

[1] Handa S. S., Khanuja S. P. S., Longo G., Rakesh D. D. (2008). Extraction Technologies for Medicinal and Aromatic Plants. International Centre for Science and High Technology, Trieste.

[2] Akinmoladun A. C., Ibukun E. O., Afor E., Akinrinlola B. L., Onibon T. L., Akinboboye A. O., Obuotor E. M., Farombi E. O. (2007). Chemical constituents and antioxidant activity of Alstonia boonei. African Journal of Biotechnology, 6(10), $1197-1201$.

[3] Okwu D. E. (1999). Medicinal plants and traditional medicine in Nigeria. Global Journal of Pure and Applied Science, 1(7), 455-459.

[4] Asongalem E. A. (2004). Anti-inflammatory, lack of central analysis and antipyretic properties of Acanthus montanus (Nees) T. Anderson. Ethnopharmacology, 95, 63- 68.

[5] Cushnie T. P. T., Lamb A. J. (2011). Recent advances in understanding the antibacterial properties of flavonoids. International Journal of Antimicrobial Agents, 38(2), 99-107.

[6] Manner S., Skogman M., Goeres D., Vuorela P., Fallarero A. (2013). Systematic exploration of natural and synthetic flavonoids for the inhibition of Staphylococcus aureus biofilms. International Journal of Molecular Sciences, 14(10), 19434-19451.

[7] Hostettmann K, Marston A. (1995). Saponins. Cambridge University Press, 1995.

[8] Stanley, M. C., Ifeanyi, O. E., Nwakaego, C. C., \& Esther, I. O. (2014). Antimicrobial effects of Chromolaena odorata on some human pathogens. Int. J. Curr. Microbiol. App. Sci, 3(3), 1006-1012.

[9] Agaba, T. A., Fawole B., Claudius-Cole, A. O. (2015). Screening of Siam Weed (Chromolaena Odorata ) and African Custard Apple ( Annona Senegalensis ) for Nematicidal Activity. Journal of Biology, Agriculture and Healthcare, 5(14), 50-57.

[10] Anushika Sirinthipaporn and Wannee Jiraungkoorskul (2017). Wound Healing Property Review of Siam Wees, Chromolaena odorata. Pharmacognosy Review, 11(21), 35-38.

[11] Otuokere, I. E., Okorie, D. O., Igwe, K. K., \& Matthew, U. J. (2016). Gas Chromatography-Mass Spectrometry Determination of Bioactive Phytocompounds in Chromolaena Odorata Leaf Extract. International Journal on Advances in Engineering Technology and Science, 7-11.

[12] Chakraborty, A. K., Sujit, R. and Umesh, K. P. (2011). Chromolaena odorata. An Overview Journal of Pharmacy Research, 43, 573-576.

[13] Oludare T. B., Olumayokun O. A., Olufunmilola S. O., Modupe M. J. (2000). Anti-inflammatory, antipyretic and antispasmodic properties of Chromolaena odorata. Pharmaceutical Biology, 38, 367370.

[14] Ling, S. K., Nor Azah, M. A., Mastura, M., Khoo, M. G. H., Saidatul Husni, S., M. Salbiah, A. Abdul Rashih, M. O. Mazura, S. Vimala, B. K. Ong, A. B. Siti Asha and A. M. Nuraini. (2007). Standardisation and formulation of Chromolaena odorata for herbal preparation. Identifying Potential Commercial Collaboratons Project Evaluation Meeting, 14-15.

[15] Maji, S., Dandapat, P., Ojha, D., Maity, C., Halder, S. K., Das Mohapatra, P. K., Mondal, K. C. (2010). In vitro antimicrobial potentialities of different solvent extracts of ethnomedicinal plants against clinically isolated human pathogens. Journal of Phytology, 2(4), 57-64.

[16] Otuokere, I. E., Okorie, D. O., Igwe, K. K., \& Matthew, U. J. (2016). Gas Chromatography-Mass Spectrometry Determination of Bioactive Phytocompounds in Chromolaena Odorata Leaf Extract. International Journal on Advances in Engineering Technology and Science, 7-11.

[17] Sekar, M., Syahira, N. U. R., \& Jalil, A. (2017). Formulation and Evaluation of Novel Antibacterial and AntiInflammatory Cream Containing Muntingia Calabura Leaves Extract, Asian Journal of Pharmaceutical and Clinical Research, 10(12), 10-13. 
[18] Harborne J. B. (1998). Phytochemical Methods: A guide to modern techniques of plant analysis. Edn 3, Chapman \& Hall, London.

[19] Offor, U. S. and Akonye, L. A. (2006). Amendment for crude oil contaminated soil with sawdust leaves for optimum plant protection. African Journal of Biotechnology, 5(9), 770-774.

[20] Robert, K. O., Nwanebu, F. C., Uduak, U., Nna ji, N., Lydia, N. O. and Nnaemeka, C. (2011). Ethanolic Extraction and Phytochemical Screening of two Nigeria Herbs Chromolaena odorata and Citrus sinensis on Pathogens Isolated from Wound Infections. International Journal of Comprehensive Pharmacy, 210.

[21] Naidoo, K. K., Coopoosamy, R. M., \& Naidoo, G. (2011). Screening of Chromolaena odorata (L.) King and Robinson for antibacterial and antifungal properties. Journal of Medicinal Plants Research, 5(19), 4859-4862.

[22] Bandar, H., Hijazi, A., Rammal, H., Hachem, A., \& Saad, Z. (2013). Techniques for the Extraction of Bioactive Compounds from Lebanese Urtica dioica. American Journal of Phytomedicine and Clinical Therapeutics, 1(6), 507-513.

[23] Chirinos R, Rogez H, Campos D, Pedreschi R, Larondelle Y. (2007). Optimization of extraction conditions ofantioxidant phenolic compounds from mashua (Tropaeolum tuberosum Ru1z \& Pavon) tubers. Sep Purif Technol, 55, 217-225.

[24] Rukshana, M., A, D., \& TP, K. P. R. (2017). Phytochemical Screening and GC-MS Analysis of Leaf Extract of Pergularia daemia (Forssk) Chiov. Asian Journal of Plant Science and Research, 7(1), 9-15.

[25] Sekar, M., Syahira, N. U. R., \& Jalil, A. (2017). Formulation and Evaluation of Novel Antibacterial and AntiInflammatory Cream Containing Muntingia Calabura Leaves Extract, 10(12), 10-13. 